\title{
Influence of Social Networks on Citizens' Willingness to Participate in Social Governance: Evidence from China
}

\author{
Rui Nan and Fan Ouyang \\ School of Law and Humanities, China University of Mining and Technology, Beijing 100083, China \\ Correspondence should be addressed to Fan Ouyang; 201123@cumtb.edu.cn
}

Received 24 June 2020; Revised 16 August 2020; Accepted 3 September 2020; Published 14 October 2020

Academic Editor: Fei Xiong

Copyright (c) 2020 Rui Nan and Fan Ouyang. This is an open access article distributed under the Creative Commons Attribution License, which permits unrestricted use, distribution, and reproduction in any medium, provided the original work is properly cited.

\begin{abstract}
Social networks are social structure constituted by a set of social actors with embedded relationships, which has a significant impact on both perceptions and behaviors among individuals and groups. The influence of the social networks on citizens' willingness to participate in social governance is manifested in two aspects: one is that social networks directly affects the citizens' willingness to participate; the other is the social capital made up by social networks, social trust, and social norms affects the citizens' willingness to participate. Drawing on a transprovincial survey regarding citizen participation in the social networks, this paper uses the Ordered Logistic model to explore how does social networks affect the citizens' willingness to participate. The results show that (1) social networks have a significant impact on citizens' willingness to participate in social governance, specifically, the stronger the social networks are, the higher level of the citizens' willingness to participate will be; (2) social networks, together with social trust and social norms constitute social capital, and the social capital has a significant impact on the citizens' willingness to participate in social governance, which is manifested; the higher the social capital stock is, the higher level of the citizens' willingness to participate will be; and (3) from the lens of demographic characteristics, those who are male, high educated, CCP members, or from the eastern region of China are more willing to participate.
\end{abstract}

\section{Introduction}

Social networks refer to the complex interpersonal networks which arise from the interaction between individual members of a society. They are social relationship system that are focused on one or some members of a society and can support their action and also a collection of various social relationships [1]. The social networks can be generally divided into informal networks and formal networks. The informal networks are a kind of interpersonal network formed through the interaction of relatives, friends, or acquaintances, showing a loose relationship not subjected to formal system constraints. The formal networks are a group pattern networks established by interest groups, nongovernmental organizations, and other institutions, which have obvious system rule constraints $[2,3]$. Practice shows that no matter what kind of social networks, they will directly affect the behavior and willingness of individuals and groups.
With the advancement of industrialization and globalization, China's social groups become more diverse and subsequently create a more diversified and personalized public demands. Hence, the social problems, which are more complicated than ever, have brought new risks and uncertainties. The citizen participation has become a pivotal approach to solve social problems and reduce social risks, as well as a policy tool to absorb various interests and value demands. From the perspective of practice, at this stage, the awareness and ability of citizen participation in China have been gradually improved, and the depth and breadth of participation have been increasingly enhanced as well. However, there are still some problems, such as weak awareness of citizen participation, weak ability, lagging laws, and regulations, which not only directly restrict the effectiveness of citizen participation in social governance but also frustrate the initiative and enthusiasm of citizen participation to a certain extent. Therefore, it is of great significance to 
advocate orderly and effective citizen participation in the implementation of social governance refinement and improve the level of social governance in China.

Orderly and efficient citizen participation depends on the certain social networks. The citizen participation in social governance refers to the participation in the field of social governance, which is an important form of social interaction. It refers to all activities in which the citizens widely participate in social governance and try to affect public policy and public life through feedback and interaction on the public policy making and the decision of public affairs or public governance. The citizen participation in social governance is not only an individual behavior but also a collective behavior centered on the public. Willingness refers to the motivation or tendency of an individual or a group to take a certain action, and the action is determined by willingness [4].

The citizen participation in social governance is a typical collective behavior. Social networks have an impact on the willingness of individuals and groups from two aspects. On the one hand, through intensive and effective social interaction, the social networks reduce the risk of information asymmetry, increase the cooperation among the citizens, promote the transformation of individual behavior into collective action, and enhance the citizens' willingness to participate [5]. On the other hand, the social capital refers to the structure, content, and perception of one's social relationships in the networks $[6,7]$. Therefore, the social networks, together with social trust and social norms constitute social capital by strengthening cooperation, mutual benefit and trust among the citizens, increase the stock of social capital, enhance the citizens' willingness to participate, and then promote the conversion of willingness into behavior $[1,5]$. Therefore, this study responds to the following questions:

(1) Whether social networks affect the citizens' willingness to participate in social governance? If so, in what manner and to what degree?

(2) Whether social capital affects the citizens' willingness to participate in social governance? If so, in what manner and to what degree?

(3) Serving as control variables, how does demographic characteristics affect the citizens' willingness to participate through social networks and social capital?

In response to the questions above, the dependent variable introduced in this research is "the citizens' willingness to participate in social governance," the independent variable is the social networks and its social capital, and the control variable is the demographic characteristics. The Ordered Logistic model is used to test the influence of social networks on the citizens' willingness to participate in social governance; and the influence of social capital composed of social networks, social norms, and social trust on the citizens' willingness; how the control variable affects the citizens' willingness through social networks and social capital.
It is known that both social networks and social governance in China have Chinese characteristics. By using certain model and taking China as the sample, this paper explores the influence and causes of China's social network on citizen participation in social governance, which may provide useful reference and enlightenment for other countries in the world. This is also the academic contribution of this paper.

\section{Related Work}

There is a rich tradition in both social science and natural science research studies that have focused on the individual or collective participation, in the perspective of social networks and social capital. Comparatively speaking, it is common to study citizen participation through social capital.

Usually in the sphere of social science, it is publicly accepted that the theoretical formulations on social capital of Bourdieu, Coleman, and Putnam have greatly contributed to the basic concept, introducing and conceptualizing it into the research of social science. In Bourdieu's opinion, social capital is the resource that provides each of the members with the backing of collective-owned capital, a credential which entitled them to credit [1], which provided a classical definition of "social capital." Coleman [8] followed Bourdieu's steps, but he emphasized the social structure which circumscribes social action, and the utility-maximizing pursuit of his/her self-interest that determines actors' goals. Putnam [9] conducted research on Italy's institutional innovation, whereas he discovered that the social capital is something which could be self-accusing and cumulative so that cooperation, trust, reciprocity, collective benefit, and civic engagement would be formed and strengthened; in addition, the networks of civic engagement fostered strong reciprocity norms. Lin [10] also has made a great contribution to the basic concepts of social networks and social capital, by trying to build a network theory of social capital, and he argued that social capital is another form of neocapital theories, which indicate access to and use of resources embedded in social networks, namely, the use of social capital by individuals. Unlike others, he discovered two conceptual elements of social capital and accordingly found out approaches in measuring social capital as assets, which expanded the individual perspective that the predecessors insisted. Obviously the basic concept they formed is used in this paper; however, the connotation of social capital and social networks in this paper is still inevitably influenced by the institutional arrangement of collectivism in People's Republic of China and the unique culture and tradition of "guanxi," which sees the individual as part of a community and a set of family, hierarchical and friendly relationships.

Based on these foundation and framework, multiple research studies have been conducted from various angles of view, such as sociology, management, political science, and economics, most of which take a certain area, or country, or enterprise as a case to study.

Some of them are still focused on the theoretical construction. Fukuyama [11] noticed that, in the Chinese parts 
of East Asia and much of Latin America, social capital resides largely in families and a rather narrow circle of personal friends; therefore, social capital in those countries have a narrow radius of trust. Ostrom [12] collected both experimental and empirical evidence to find out the explanations to collective actions, which is development and growth of social norms. Glaeser et al. [13] tried to probe into an economic approach to social capital, and they found out the interpersonal externalities could be generated by social capital, which bring about the difference between social capital and other forms of capital; in addition, the social capital accumulation patterns are consistent with the standard economic investment model. Roberts and Devine [14] suggested that a major factor in the individuals' volunteering, who are involved in numerous forms of voluntary activity, is the pleasure and enjoyment they would gain from the activity itself; therefore, a constant process of dialogue within formal structures of participation is needed. Fu [15] found out that social capital and trust are mutually reinforcing, namely, social capital generates trusting relationship while in turn trust produces social capital. Those help our research design to take notice on the difference among regions and the difference between rural and urban areas.

In recent year, it is more popular to take a certain area, or country, or enterprise as the case to probe into. Brewer [16] conducted a research based on the data from 1996 American National Election Study, comparing public servants and other citizens with regard to attitudes and behaviors related to social capital, with the conclusion that public servants are far more active in civic affairs than other citizens. Skoric et al. [17] followed Putnam's pattern, trying to examine whether the social networks on the Internet could pave the paths for revival of political participation both online and offline in Singapore. Torri [18] examines GMCL, an Indian community-based enterprise led by women which is formed by a network of self-help groups, arguing that group and social forms of entrepreneurship should not become the paradigm in developmental policies for women. Fung and Hung [19] explored developing sustaining social capital for community development based on their case study on the Tin Shui Wai North in Hongkong. Asteria et al. [20] discovered by a quantitative approach that puts efforts to increase women's participation in urban planning and environmental management require the support of social capital. Suh and Heidi [21] revealed a positive association between outgroup trust and protest participation, moderated by both functioning institutions and state repression.

The above studies provide different social science' perspectives to discuss social networks and citizen participation; however, they are mainly based on the Western social background, which may not adequate to explain the reality of social networks in China and how it influences the citizens' willingness to participate and what measures could be taken to foster and reinforce the social networks so that the social capital could grow.

Meanwhile, the concepts of social capital, participation, social networks, social norms, social recommendation, etc., also began to attract the attention of the sphere of natural science. Zúñiga's et al. [22] research disclosed that information use of social networks sites exerted a significant and positive impact on individuals' activities aimed at engaging in civic and political action. Hu et al. [23] introduced evolutionary opinion dynamics from the field of statistical physics into the recommender system, measuring user influence according to their topological role in the social networks, in order to predict the unknown ratings. Xiong et al. [24] also conducted experiments on real-world datasets to compare the proposed method with the state-of-the-art models, and the results indicate that the social recommendation method makes notable improvements in rating prediction. Li et al. [25] found the importance of users' ratings and determine their influence on entire social networks analyzing the topology of social networks to investigate users' influence strength on their neighbors. The above research studies provide a technical insight for our research and an adequate approach to prove and support our research.

\section{Data and Model}

3.1. Theoretical Analysis and Hypothesis. To some extent, the interpersonal networks formed by social networks are both a valuable resource and a media. The stronger the social networks are, the more rapid and effective the information transmission and diffusion are. They can reduce the information bias in the citizen participation in social governance, effectively alleviate moral hazard, reduce the transaction cost of social interaction, promote the formation of orderly cooperative behavior, and thus enhance the citizens' willingness to participate in social governance. In addition, social networks, together with social trust and social norms, constitute social capital. It is not only a sort of resource, "social structure resource possessed by individuals," or "a resource embedded in a social structure that could be acquired or mobilized in the purposeful actions," whereas others consider social capital as a kind of ability, "the ability that individuals maintains precious resources in the networks or in a much wider social structure, through the membership" $[5,8,10]$. The social capital, through the coordination of social networks, restriction of social norms, and the support of social trust, promotes the public's collective action, which helps to improve the public's rule obedience, and promotes the public's sense of self-interest to public welfare which effectively solves the collective action dilemma, and improves the citizens' willingness to participate in social governance [26, 27]. Among them, "trust is a particular level of the subjective probability with which an agent assesses that another agent or group of agents will perform a particular action, both before he can monitor such action (or independently of his capacity ever to be able to monitor it) and in a context in which it affects his own action" [28]; norms are "shared understandings about actions that are obligatory, permitted, or forbidden" [29]; networks are the carrier of social capital, postulating "that human behavior is embedded in a network of interpersonal relations" [30]. Based on these, the following research hypotheses are proposed: 
$H_{1}$ : the stronger the social networks are, the stronger the citizens' willingness to participate in social governance is.

$\mathrm{H}_{2}$ : the higher stock of social capital is, the stronger the citizens' willingness to participate in social governance is.

$H_{2 a}$ : the higher level of social trust is, the stronger the citizens' willingness to participate in social governance is.

$\mathrm{H}_{2 b}$ : the higher level of social norms is, the stronger the citizens' willingness to participate in social governance is.

Based on previous studies, the citizens' willingness to participate in social governance can be affected by the demographic characteristics, including gender, age, education, income, and region [31-33]. Therefore, the following hypothesis is formulated:

$\mathrm{H}_{3}$ : demographic characteristics (gender, age, education, political status, income, and region) strongly affect the willingness of citizen participation in social governance.

3.2. Data Source and Validation. The research utilized the Stratified Sampling method to collect the first-hand data. The stratification of this survey was conducted firstly on the basis of the division of three economic belts (Eastern, central, and Western) in China (five provinces from each), and then the sample was drawn according to the population proportion and the sex ratio (roughly equivalent) (according to the level of economic development and geographical location, China can be divided into three regions). On the basis of the three economic belts, the first layer comprised of five more developed provinces or municipalities in Eastern China: Beijing, Guangdong, Zhejiang, Shandong, and Fujian; the second layer comprised of five medium-developed provinces in Central China: Hubei, Anhui, Henan, Hunan, and Jilin; the third layer was comprised of five underdeveloped provinces or autonomous regions in Western China: Yunnan, Shaanxi, Sichuan, Inner Mongolia, and Gansu. The survey was conducted both online and offline, among which the online survey covered all the 15 provinces, municipalities or autonomous regions, while the offline survey covered Beijing, Guangdong, and Zhejiang in the Eastern region, Hubei and Anhui in the Central region, and Yunnan and Shaanxi in the Western region. There were 773 valid questionnaires out of the 1037 questionnaires (74.54\%) obtained from online survey, while there were 232 valid questionnaires out of the amount of 250 questionnaires (92.8\%) obtained from offline survey.

In order to ensure the reliability and validity of the survey, the respondents were limited to $18-65$ years old, and Stratified Sampling method was adopted in the survey process. The test results were shown that the Cronbach Alpha Coefficient is 0.891, which means the internal consistency is good; while the $\mathrm{KMO}=0.783$, and the significance level of Bartlett's test of sphericity $=0.000$, indicating the survey is of high validity.

\subsection{Variable Designing and Measurement}

3.3.1. Dependent Variables. The dependent variable is "the citizens' willingness to participate in social governance (willingness)," measured mainly by asking the respondents the question "your willingness of participating in social governance." The respondents could choose among the four options, "not willing at all," "willing to participate in all the available activities," "willing to participate in the activities of easy access," and "willing to participate in the activities of easy access, with self-interests involved," which was an ordinal categorical variable, on a scale from 1 to 4 .

3.3.2. Independent Variables. The independent variable is the social networks and its social capital. Social capital was divided into three parts, social networks, social trust, and social norms, according to Putnam's definition, and measured by the three parts as well. They were, respectively, marked as below: networks, capital, trust, and norms. The scale for measuring these variables is designed according to the characteristics of China's social capital and social networks based on the previous research [34-38]. The scale focuses on the measurement of community microsocial capital and social networks, focusing on the impact of collective participation behavior from the macroperspective.

As for the measurement of social networks, there were also two questions: Q1 was "how many neighbors do you greet frequently in your community (village)," and the options were "<30," "30-39," "40-49," "50-60," and " $\geq 60$," on a scale from 1 to 5; Q2 was "how many neighbors are considered to be your friends in your community (village)," and the options were "<5," " $5-7$," " $8-10$," " $11-15$," and "> 15 ," on a scale from 1 to 5 .

Likert Scale was used to measure "social trust," mainly on the levels of trust of plural participants in social governance; then, four questions were set up, about the levels of trust on the four kinds of participants' participation in social governance, that is, the government (or CPC committee), social organizations, self-organizations, and other publics. There were five options: "completely trust," "somewhat trust," "moderately trust," "somewhat distrust," and "distrust completely," on a scale from 1 to 5 .

Concerning "social norms," two questions were set up based on the previous research studies: Q1 was "how difficult do you think it is to acquire the relevant information on social governance?" along with five options that were "completely difficult," "somewhat difficult," "moderately difficult," "somewhat easy," and "completely easy," on a scale from 1 to 5; Q2 was "to what degree do you understand the overall policy and regulations (or institutions) on social governance?", along with five options, which were "completely do not understand," "somewhat do not understand," "moderately understand," "somewhat understand," and "completely understand," on a scale from 1 to 5 (each dimension is set with 4-5 items, and only items with passing factor load (at least greater than 0.4 ) is listed here).

3.3.3. Control Variables. The control variables are gender, age, education, political status, occupation, income, urban or rural status, and region, respectively, marked as gender, age, 
education, CPC membership, occupation, income, urban or rural, and region. The variable' scaling and statistical description are as shown in Table 1.

3.4. Model. According to the practices, the citizens' willingness to participate in social governance could be divided into four categories: "no willing at all," "willing to participate in all the available activities," "willing to participate in the activities of easy access," and "willing to participate in the activities of easy access, with self-interests involved," which are typical ordinal categorical variables with clear stratifications; therefore, the Ordinal Logistic model was used as the primary empirical model in this research. The logic diagram is shown in Figure 1.

The specific process is as follows [39]:

$$
y_{i}^{*}=\beta_{i} x_{i}+\mu_{i} .
$$

In this model, $i$ refers to the $i$ th specific citizen; $y_{i}^{*}$, an unobservable variable, refers to the different levels of willingness of citizen participation in social governance; $x_{i}$ is the vector of a group of explanatory variables which might influence the citizens' willingness to participate in social governance; $\beta_{i}$ is the coefficient of correspondence to the explanatory variables; and $\mu_{i}$ is the random error term.

There are four categorical levels on the citizens' willingness to participate in social governance, as the following: $y_{i}=1$ refers to "no willing at all," $y_{i}=2$ refer to "willing to participate in all the available activities," $y_{i}=3$ refers to "willing to participate in the activities of easy access," and $y_{i}=4$ refers to "willing to participate in the activities of easy access, with self-interests involved." There are three cutoff points (thresholds) as below:

$$
y_{i}= \begin{cases}1, & y_{i} \leq \mu_{1}, \\ 2, & \mu_{1}<y_{i} \leq \mu_{2}, \\ 3, & \mu_{2}<y_{i} \leq \mu_{3}, \\ 4, & y_{i}>\mu_{3} .\end{cases}
$$

Assuming $\mu_{i}$ is subject to the Logistic distribution, and the distribution function is $F_{(x)}$, that is,

$$
\begin{aligned}
& \left\{\begin{array}{l}
p_{r}\left(y_{i}=1 \mid x_{i}\right)=1-F_{\left(\beta_{i} x_{i}\right)}, \\
p_{r}\left(y_{i}=2 \mid x_{i}\right)=F_{\left(\mu_{1}-\beta_{i} x_{i}\right)}, \\
p_{r}\left(y_{i}=3 \mid x_{i}\right)=F_{\left(\mu_{2}-\beta_{i} x_{i}\right)} \\
p_{r}\left(y_{i}=4 \mid x_{i}\right)=1-F_{\left(\mu_{3}-\beta_{i} x_{i}\right)}
\end{array}\right. \\
& F_{\left(\beta_{i} x_{i}\right)}=\frac{\exp (\beta x)}{1+\exp (\beta x)} .
\end{aligned}
$$

In order to better analyze the alteration of the level of the citizens' willingness to participate in social governance, the marginal effect was also adopted to analyze the degree of influence on the citizens' willingness to participate so that the change of social networks and social capital has

$$
\left\{\begin{array}{l}
\frac{\partial p_{r}\left(y_{i}=1 \mid x_{i}\right)}{\partial x_{i}}=-f_{\left(-\beta_{i} x_{i}\right)} \beta_{i}, \\
\frac{\partial p_{r}\left(y_{i}=2 \mid x_{i}\right)}{\partial x_{i}}=f_{\left(\mu_{1}-\beta_{i} x_{i}\right)}-f_{\left(-\beta_{i} x_{i}\right)} \beta_{i}, \\
\frac{\partial p_{r}\left(y_{i}=3 \mid x_{i}\right)}{\partial x_{i}}=f_{\left(\mu_{2}-\beta_{i} x_{i}\right)}-f_{\left(-\beta_{i} x_{i}\right)} \beta_{i}, \\
\frac{\partial p_{r}\left(y_{i}=4 \mid x_{i}\right)}{\partial x_{i}}=f_{\left(\mu_{3}-\beta_{i} x_{i}\right)} \beta_{i} .
\end{array}\right.
$$

The measurement of social capital involves many indexes, so it is necessary to make factor analysis. The specific process is as follows.

Let social capital have $m$ common factors, namely, $f_{1}$, $f_{2}, \ldots, f_{m}$. General assumption $X_{1}, X_{2}, \ldots, X_{p}$ is the sum of these common factors and their special factors $\varepsilon_{1}, \varepsilon_{2}, \ldots, \varepsilon_{p}$ composition:

$$
X_{i}=a_{i 1} f_{1}+a_{i 2} f_{2}+\ldots+a_{i m} f_{m}+\varepsilon_{i}, \quad(i=1,2, \ldots, p, m \leq p) .
$$

It is expressed in the matrix form as follows:

$$
X=A F+\varepsilon,
$$

where

$$
\begin{aligned}
X & =\left[\begin{array}{l}
X_{1} \\
X_{2} \\
\cdots \\
X_{P}
\end{array}\right], \\
F & =\left[\begin{array}{l}
f_{1} \\
f_{2} \\
\cdots \\
f_{P}
\end{array}\right], \\
A & =\left[\begin{array}{llll}
a_{11} & a_{12} & \cdots & a_{1 m} \\
a_{21} & a_{22} & \cdots & a_{2 m} \\
\cdots & \cdots & \cdots & \cdots \\
a_{p 1} & a_{p 2} & \cdots & a_{p m}
\end{array}\right], \\
\mathcal{E} & =\left[\begin{array}{l}
\varepsilon_{1} \\
\varepsilon_{2} \\
\cdots \\
\varepsilon_{P}
\end{array}\right] .
\end{aligned}
$$

$E(X)=0, \operatorname{cov}(X, X)=R, R$ is the correlation coefficient matrix, $\quad E(F)=0, \quad$ and $\operatorname{cov}(F, F)=I_{m}(M-$ order unit matrix), that is, there is no correlation between the common factors and the variance is 1 .

$$
E(\varepsilon)=0, \operatorname{cov}(\varepsilon, \varepsilon)=\left[\begin{array}{cccc}
\sigma_{1}^{2} & 0 & \cdots & 0 \\
0 & \sigma_{2}^{2} & \cdots & 0 \\
0 & 0 & \ddots & 0 \\
0 & 0 & \cdots & \sigma_{p}^{2}
\end{array}\right]=\varnothing \text {, that is, each }
$$

special factor is not related, and the variance does not need to be equal. 
TABLE 1: Ordinal logistic model variable scaling and statistics.

\begin{tabular}{|c|c|c|c|}
\hline Category & Variables & Scaling & Ratio (\%) \\
\hline \multirow{4}{*}{ Dependent } & \multirow{4}{*}{ Willingness of participate } & $1=$ no willing at all & 36.82 \\
\hline & & $2=$ willing to participate in all the available activities & 19.50 \\
\hline & & $3=$ willing to participate in the activities of easy access & 35.22 \\
\hline & & $4=$ willing to participate in the activities of easy access, with self-interests involved & 8.46 \\
\hline \multirow{4}{*}{ Independent } & Social networks & $\mathrm{PCS}^{1}$ & - \\
\hline & Social capital & PCS & - \\
\hline & Social trust & PCS & - \\
\hline & Social norms & PCS & - \\
\hline & \multirow[b]{2}{*}{ Gender } & $0=$ male & 53.33 \\
\hline & & $1=$ female & 46.67 \\
\hline & \multirow{4}{*}{ Age } & $1=18-29$ & 42.49 \\
\hline & & $2=30-39$ & 29.35 \\
\hline & & $3=40-49$ & 21.89 \\
\hline & & $4 \geq 50$ & 6.27 \\
\hline & \multirow{3}{*}{ Education } & $1=$ junior secondary school or lower & 20.50 \\
\hline & & $2=$ senior secondary school or specialized secondary school & 27.06 \\
\hline & & $3=$ short-cycle courses in HEIs or above & 52.44 \\
\hline & & $0=$ No & 32.44 \\
\hline & CPC membership & $1=$ Yes & 67.56 \\
\hline \multirow{13}{*}{ Control } & \multirow{5}{*}{ Occupation } & $1=$ government, public institutions, and state-owned enterprises & 27.16 \\
\hline & & $2=$ private enterprises & 39.20 \\
\hline & & $3=$ farming & 11.64 \\
\hline & & $4=$ others & 21.99 \\
\hline & & $1 \leq 3000$ yuan & 36.72 \\
\hline & \multirow{3}{*}{ Income (CNY) } & $2=3000-4500$ yuan & 22.89 \\
\hline & & $3=4501-9000$ yuan & 26.47 \\
\hline & & $4 \geq 9000$ yuan & 13.93 \\
\hline & \multirow{3}{*}{ Urban or rural } & $0=$ urban & 70.55 \\
\hline & & $1=$ rural & 29.45 \\
\hline & & $1=$ eastern & 43.38 \\
\hline & \multirow[t]{2}{*}{ Region } & $2=$ central & 36.02 \\
\hline & & $3=$ western & 20.60 \\
\hline
\end{tabular}

${ }^{1}$ PCS was the main component factor score

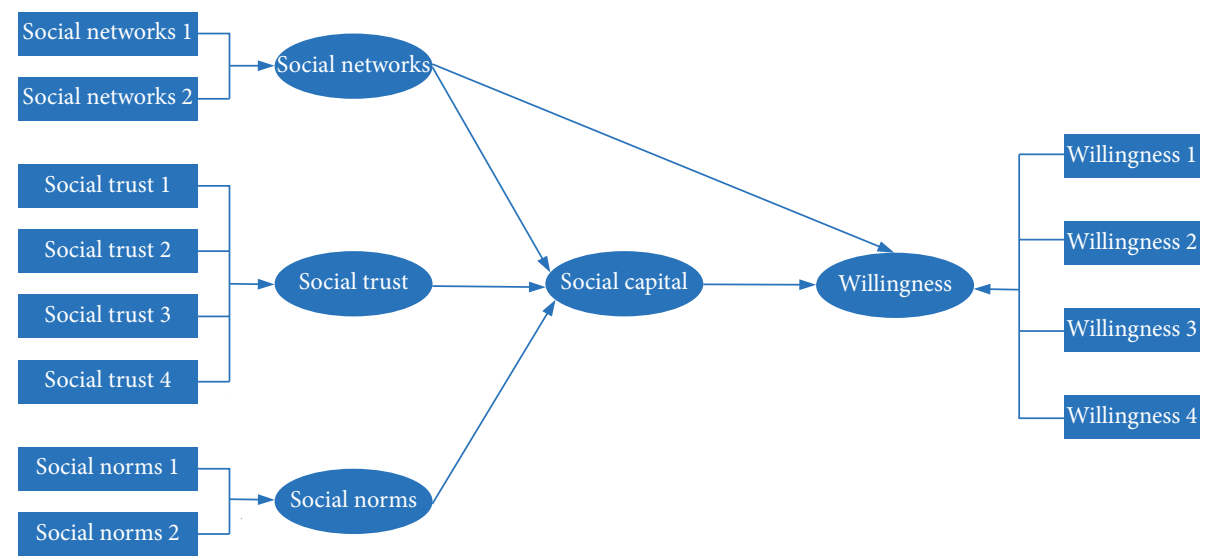

Figure 1: Model logic diagram.

$\operatorname{cov}(F, \varepsilon)=0$, that is, the common factor and the special factor are not related. $X$ is an observable random vector, while $F$ and $\varepsilon$ are unobservable random vectors.

In the factor analysis model, matrix $A$ is called factor load matrix. Record $A=\left(a_{i j}\right)_{p \times m}$ :

$$
\begin{aligned}
\operatorname{cov}\left(X_{i}, f_{j}\right) & =\operatorname{cov}\left(a_{i 1} f_{1}+a_{i 2} f_{2}+\cdots+a_{i m} f_{m}+\varepsilon_{i}, f_{j}\right) \\
& =\operatorname{cov}\left(a_{i j} f_{j}, f_{j}\right)=a_{i j} \operatorname{cov}\left(f_{j}, f_{j}\right) \\
& =a_{i j}, \quad(i=1,2, \ldots, p, j=1,2, \ldots, m),
\end{aligned}
$$


where $a_{i j}$ is the correlation coefficient between variable $X_{i}$ and common factor $f_{j}$, i.e., factor load. It is the load of the $i$ variable $X_{i}$ on the $j$ factor $f_{j}$.

\section{Results and Analysis}

Based on Sherry Arnstein's "Ladder of Citizen Participation" [40], along with the practice of social governance in China, the citizens' willingness to participate in social governance was divided into three types according to the levels of participation intensity (Table 2 ).

It is shown in Table 2 and Figure 2 that, according to the levels of participation intensity, the willingness to participate in social governance could be divided into three types which are strong participation, weak participation, and limited participation. Level 1 and level 2, respectively, corresponded to the willingness of "no willing at all" and "willing to participate in all the available activities," with the participation degrees of extremely weak and extremely strong, which were put into the two types of "weak participation" and "strong participation." In the middle, there were level 3 and level 4, respectively, corresponding to the willingness of "willing to participate in the activities of easy access," and "willing to participate in the activities of easy access, with self-interests involved," with the degrees of "relatively strong" and "relatively weak," which were put into the type of "limited participation." Concerning the ratio, the type of strong participation possessed the least proportion of 19.5\%; the ratio of the public of limited participation was relatively higher, which was $43.68 \%$; and the ratio of weak participation reached as high as $36.82 \%$, which indicated the overall level of the citizens' willingness to participate in social governance is still on the low side in China.

4.1. Descriptive Statistics. It is obvious in Table 3 that, from the nationwide perspective, on the citizens' willingness to participate in social governance, $36.82 \%$ of the respondents are not willing to participate in and $63.18 \%$ of them are willing to participate in, among which $19.50 \%$ of them have strong willingness of participation, namely, intending to participate in all the available activities; $35.22 \%$ of them willing to participate in the activities of easy access, and $8.46 \%$ of them intend to willing to participate in the activities of easy access, with self-interests involved. In the Eastern region in China, the proportion of respondents who have "no willingness at all" fell to around $20 \%(23.39 \%)$, while that of respondents approximates to (or exceeds) 50\% (45.03\% and $50.72 \%$ ) in Central and Western regions. It indicates that, the nationwide willingness of citizen participation in social governance is relatively strong, though more falling into the limited-participation type, which including the two willingness types of "willing to participate in the activities of easy access" and "willing to participate in the activities of easy access, with self-interests involved." From the comparison of three regions, the citizens' willingness to participate in social governance in the Eastern region is relatively stronger, the central region takes the second place, and the Western region is relatively weaker; in addition, there are more limited-participation citizens in the Eastern region, with their willingness mainly displayed as limited participation.

It is shown in Figure 3 as follows:

(1) Gender and willingness to participate: the ratio of female respondents who are not willing to participate in social governance is higher than that of male, and the ratio of male is higher than female on the three levels of relatively stronger willingness of participation, especially on the "categorical level $=2$," and the participation willingness of males is apparently higher than that of females. It suggests that the male's willingness of participation in social governance is higher than that of female.

(2) Age and willingness to participate: the ratio of the respondents above 40 years old (middle aged) who are not willing to participate in social governance is relatively higher, while the younger respondents make up a smaller proportion. On the three different levels of willingness, the ratios of respondents from different age groups are roughly equal, without apparent disparity, though they are still concentrated on the latter two levels, namely, the limited participation, which indicates that, comparatively, the participation willingness of middle-aged citizens is weaker than that of young citizens; however, among the citizens from different age groups, there is little difference on the three levels of willingness to participation in China and more on the limited-participation type (for the division of middle-aged and young people, this paper adopts the standard of all China Youth Federation and considers that $18-40$ years old are young people).

(3) Education and willingness to participate: The ratio of the respondents with college degree or above (well educated) with no willing to participate in social governance is well below the other two categories, and the ratio of the respondents with degrees of senior secondary school or lower is relatively higher. To be more specific, for the well-educated respondents, the ratio of citizens who are "willing to participate in the activities of easy access" accounts for a higher proportion, whereas the ratio of the citizens who are "willing to participate in the activities of easy access, with self-interests involved" is relatively insensitive to the education factor, which indicated that, relatively, the citizens with higher education have stronger willingness to participate in social governance in China.

(4) Political status and willingness to participate: the ratio of the citizens who are CPC members is lower than the non-CPC members on the "no willing at all" level, and the CPC members' participation willingness relatively concentrates on the "categorical lev$\mathrm{el}=3$," which suggests the willingness of 
TABLE 2: Types of willingness to participate in social governance.

\begin{tabular}{lcc}
\hline Categorical level & Willingness & Types of willingness to participate \\
\hline 1 & No willing at all & Weak participation \\
2 & Willing to participate in all the available activities & Strong participation \\
3 & Willing to participate in the activities of easy access & Limited participation \\
4 & Willing to participate in the activities of easy access, with self-interests involved & \\
\hline
\end{tabular}



FIGURE 2: Statistical analysis of willingness in social governance.

TABLE 3: Analysis on the citizens' willingness to participate in social governance.

\begin{tabular}{lccccc}
\hline \multirow{2}{*}{ Region } & Gross sample & \multicolumn{4}{c}{$\begin{array}{c}\text { Ratio of the citizens from different } \\
\text { categorial levels (\%) }\end{array}$} \\
& & 1 & 2 & 3 & 4 \\
\hline National & 1005 & 36.82 & 19.50 & 35.22 & 8.46 \\
Eastern & 436 & 23.39 & 9.86 & 43.81 & 22.94 \\
Central & 362 & 45.03 & 6.91 & 29.56 & 18.51 \\
Western & 207 & 50.72 & 8.21 & 27.05 & 14.01 \\
\hline
\end{tabular}

participation in social governance of the citizens with CPC membership is stronger than the citizens without CPC membership.

(5) Occupation and willingness to participate: the respondents in farming account for a relatively higher proportion (49.57\%) on the level "no willing at all," whereas the participation willingness of the respondents within the system (government, public institutions, and state-owned enterprises) is relatively stronger $(38.83 \%$ and $21.61 \%)$. It reveals that the citizens within the system has comparatively stronger willingness of participation in social governance, that of the citizens working in private enterprises ranks the next, and that of the citizens in farming is relatively lower.

(6) Income and willingness to participate: the proportion of "no willing at all" among the respondents of high-income (>9000) group and low-income $(<3000)$ groups is relatively larger, whereas the proportion among the respondents of middle income is relatively small. All the groups concentrate on the "categorical level =3," while middle-income group accounts for the largest proportion on the "categorical level $=2$," which reveals that the citizens from middle-income group have stronger willingness of participation in social governance; moreover, the degree of their willingness is relatively higher (in this paper, according to the per capita M2 (9360.5 yuan) and per capita GDP (4493.5 yuan) of China in 2016, the personal income level is divided into lowincome $(I<3000$ yuan), low-income $\quad(3000$ yuan $<I<4500$ yuan), middle-income $\quad(4500$ yuan $<I<9000$ yuan), and high-income ( $I>9000$ yuan), in which $I$ is the average monthly income).

(7) Urban or rural status and willingness to participate: the respondents living in rural areas account for a relatively higher ratio of the level of "no willing at all," while the urban respondents concentrating on the latter two levels, namely, limited-participation. On the "categorical level=2," the ratio of the rural respondents is higher than that of the urban respondents. As a whole, the willingness of the citizens in the urban areas is relatively stronger, yet the willingness of the citizens in the rural areas is stronger than that of the citizens in the urban areas when it comes to the type of "willing to participate in the activities of easy access."

4.2. Analysis on Econometric Results. In general, descriptive statistics is a kind of data analysis tools, direct and simple, and easy to operate. However, it is difficult for descriptive statistics to describe the correlations of multiple variables, which should be analyzed through a certain econometric model, taking the results of descriptive statistics as evidence.

4.2.1. Measurement of Social Capital. There are many indicators involved in the measurement of social capital, so conducting factor analysis would be necessary. The result 


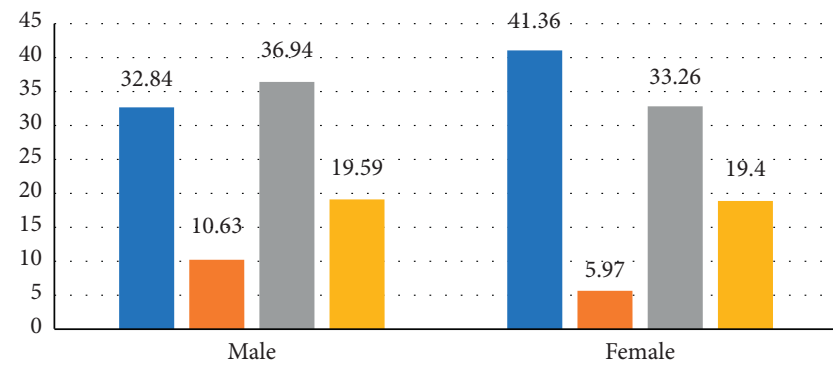

- Not willing at all

- Willing to participate in all the available activities

Willing to participate in the activities of easy access

- Willing to participate in the activities of easy access, with self-interests involved

(a)

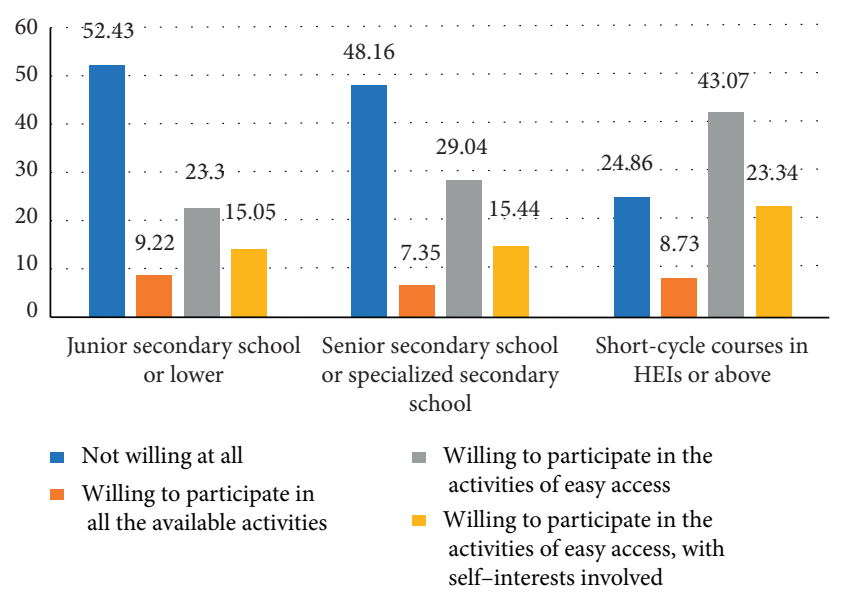

(c)

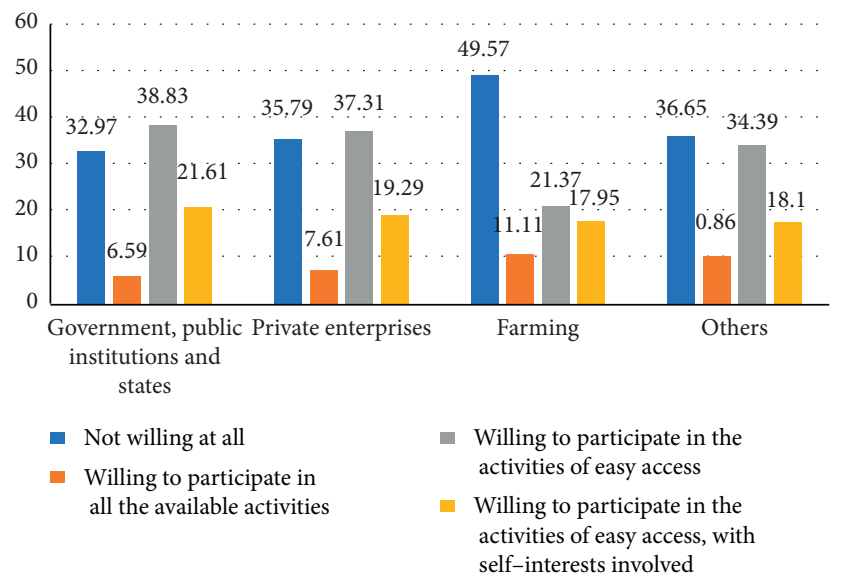

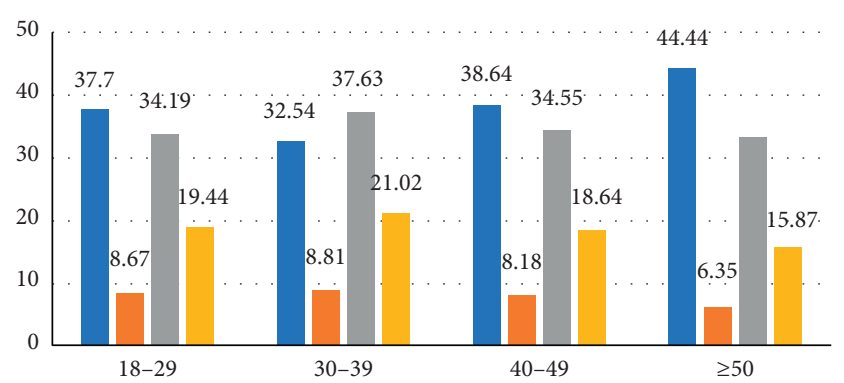

- Not willing at all

- Willing to participate in all the available activities

- Willing to participate in the activities of easy access

- Willing to participate in the activities of easy access, with self-interests involved

(b)

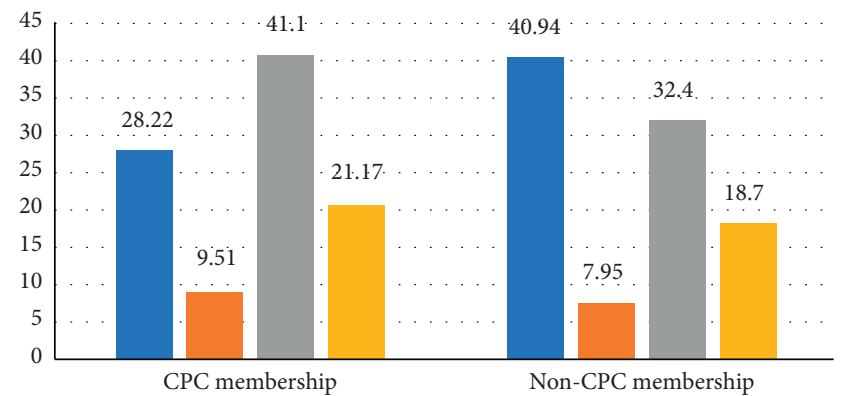

- Not willing at all

- Willing to participate in all the available activities
- Willing to participate in the activities of easy access

- Willing to participate in the activities of easy access, with self-interests involved (d)

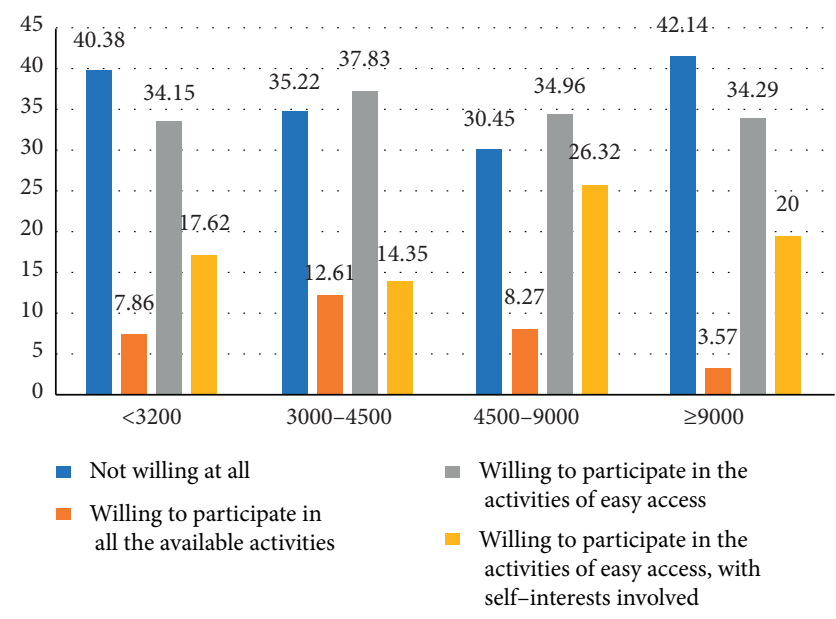

Figure 3: Continued. 


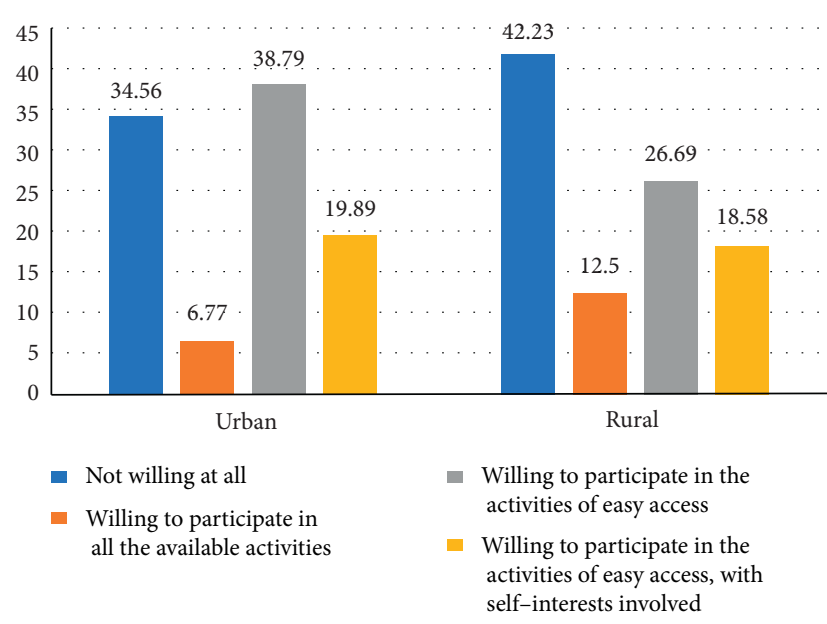

(g)

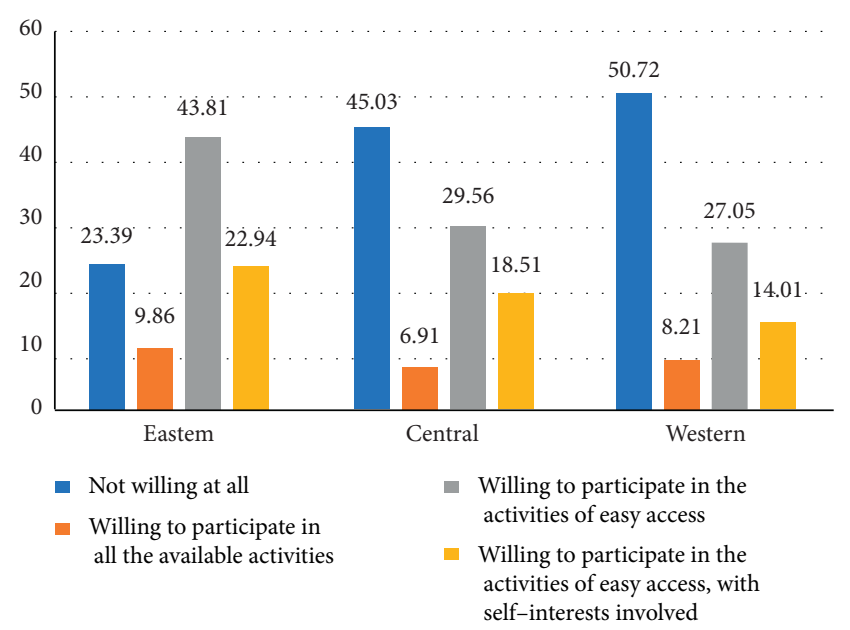

(h)

FIgURE 3: Analysis of the citizens' willingness to participate in social governance based on multifactors. (a) Statistics of citizen participation willingness of different genders. (b) Statistics of citizen participation willingness of different ages. (c) Statistics of citizen participation willingness of different education backgrounds. (d) Statistics of citizen participation willingness of different political situations. (e) Statistics of citizen participation willingness of different occupations. (f) Statistics of citizen participation willingness of different incomes. (g) Statistics of citizen participation willingness of urban and rural. (h) Statistics of citizen participation willingness of different regions.

of adaptability test shows that the KMO value of the sample test is 0.783 (greater than 0.6 ), indicating that it is adequate to build the factor analysis model, and the significance level of Bartlett's test of sphericity to the samples is $0.000(<0.01)$, indicating the correlation between the variables is significant, so as to be suitable for factor analysis. Orthogonal rotation was conducted by the varimax method, in accordance with the principle of eigen values $>1$, and the first three Eigen factor values are all greater than 1.00, and the cumulative variance contribution rate amounts to $72.563 \%$, greater than $70 \%$; then, three common factors could be extracted, and the details are shown in Table 4:

It is suggested in Table 4 that the first common factor has great factor loadings on "trust on the government," "trust on the social organizations," "trust on NGOs," and "trust on the public," concentrating on the dimension of social trust, so it is called "social trust factor;" the second common factor has great factor loadings on "how many neighbors do you greet frequently in your community (village)" and "how many neighbors that are considered to be your friends in your community (village)," concentrating on the dimension of social networks, so it is called "social network factor;" and the third common factor has great factor loadings on "how difficult do you think it is to acquire the relevant information on social governance?" and "to what degree do you understand the overall policy and regulations (or institutions) on social governance?," concentrating on the dimension of social norms, so it is called "social norm factor." As a whole, the result is compatible with the theoretical hypothesis of this research, namely, the three-dimension interpretation of social capital, and it also demonstrates the adequate structural validity of the questionnaire.
4.2.2. Analysis of the Influence of Social Networks and Its Social Capital on the Citizens' Willingness to Participate in Social Governance. In order to better test the robustness of the model result, OLS was introduced to conduct comparative analysis while estimating [41], on the basis of the consistency on the direction of parameter estimation and significance between OLS and the Maximum Likelihood Estimate of Ordinal Logistic. The specifics are shown in Table 5.

The Nested Model was used to verify the research hypothesis: model 1 and model 3 are in the same group, comprised of control variables and dependent variables-social networks, social trust, and social norms-and their influence on the citizens' willingness to participate in social governance was analyzed by the method of Maximum Likelihood Estimate based on OLS and Ordinal Logistic. Likewise, model 2 and model 4 are in the same group, comprised of control variable and dependent variable-social capital-and the influence of the whole of social capital including social networks on the citizens' willingness to participate in social governance was analyzed by the method of Maximum Likelihood Estimate based on OLS and Ordinal Logistic, in order that the impact of the social capital's endogeneity problem could be excluded.

In general, with the significance level of $5 \%$, the results of either Ordinal Logistic estimation, or OLS estimation, indicate that, the social networks and social capital have significant influence on the citizens' willingness to participate in social governance, so do the demographic characteristics "gender," "education," "political status," and "region," whereas the other characteristics "age," "occupation," "income," and "urban or rural status" do not.

Since the results of parameter estimation in the ordinal logistic model could not clarify the direction and degree of influence between variables at different categorical levels, but 
TABLE 4: Result of factor analysis on social capital.

\begin{tabular}{|c|c|c|c|}
\hline \multirow{2}{*}{ Measurement item } & \multicolumn{3}{|c|}{ Principal factor } \\
\hline & 1 & 2 & 3 \\
\hline How many neighbors do you greet frequently in your community (village) & -0.047 & 0.847 & -0.060 \\
\hline How many neighbors that are considered to be your friends in your community (village) & 0.011 & 0.839 & -0.078 \\
\hline How difficult do you think it is to acquire the relevant information on social governance? & -0.019 & -0.015 & 0.831 \\
\hline To what degree do you understand the overall policy and regulations (or institutions) on social governance? & 0.000 & -0.123 & 0.804 \\
\hline Trust on the government & 0.834 & -0.023 & 0.016 \\
\hline Trust on the social organizations & 0.894 & -0.007 & -0.035 \\
\hline Trust on the NGOs & 0.878 & 0.004 & -0.018 \\
\hline Trust on other publics & 0.866 & -0.033 & 0.002 \\
\hline Eigen values & 3.018 & 1.438 & 1.349 \\
\hline$\%$ of variance & 37.727 & 17.978 & 16.859 \\
\hline Cumulative $\%$ of variance & 37.727 & 55.705 & 72.563 \\
\hline
\end{tabular}

Method of extraction: PCA. Rotation: Kaiser-Varimax rotation.

TABle 5: Regression analysis results of social networks, social capital, and demographic characteristics on the citizens' willingness to participate in social governance.

\begin{tabular}{|c|c|c|c|c|c|c|}
\hline \multirow{2}{*}{ Variables } & \multicolumn{3}{|c|}{ Ordinal logistic model } & \multicolumn{3}{|c|}{ OLS model } \\
\hline & (1) & (2) & (3) & (4) & (5) & (6) \\
\hline Gender & $\begin{array}{c}-0.4463^{*} \\
(0.1197)\end{array}$ & $\begin{array}{c}-0.4855^{*} \\
(0.1207)\end{array}$ & $\begin{array}{c}-0.4324^{*} \\
(0.1218)\end{array}$ & $\begin{array}{c}-0.2358^{*} \\
(0.0618)\end{array}$ & $\begin{array}{c}-0.2473^{*} \\
(0.0612)\end{array}$ & $\begin{array}{c}-0.2177^{*} \\
(0.0613\end{array}$ \\
\hline Age & $\begin{array}{l}-0.0395 \\
(0.0640)\end{array}$ & $\begin{array}{c}-0.0620 \\
((0.0646)\end{array}$ & $\begin{array}{l}-0.0701 \\
(0.0648)\end{array}$ & $\begin{array}{l}-0.0212 \\
(0.0331)\end{array}$ & $\begin{array}{l}-0.0311 \\
(0.0328)\end{array}$ & $\begin{array}{c}-0.0348 \\
(0.0326)\end{array}$ \\
\hline Education & $\begin{array}{l}0.4832^{*} \\
(0.0781)\end{array}$ & $\begin{array}{l}0.4606^{*} \\
(0.0786)\end{array}$ & $\begin{array}{l}0.4828^{*} \\
(0.0792)\end{array}$ & $\begin{array}{l}0.2397^{*} \\
(0.0397)\end{array}$ & $\begin{array}{l}0.2239^{*} \\
(0.0394)\end{array}$ & $\begin{array}{c}0.2335^{*} \\
(0.0392)\end{array}$ \\
\hline Political status & $\begin{array}{l}0.4031^{*} \\
(0.1282)\end{array}$ & $\begin{array}{l}0.3691^{*} \\
(0.1287)\end{array}$ & $\begin{array}{l}0.3973^{*} \\
(0.1294)\end{array}$ & $\begin{array}{c}0.2125^{*} \\
(0.0656)\end{array}$ & $\begin{array}{c}0.1904^{*} \\
(0.0653)\end{array}$ & $\begin{array}{c}0.2041^{*} \\
(0.0654)\end{array}$ \\
\hline Occupation & $\begin{array}{c}0.0370 \\
(0.0601)\end{array}$ & $\begin{array}{c}0.0538 \\
(0.0604)\end{array}$ & $\begin{array}{c}0.0500 \\
(0.0608)\end{array}$ & $\begin{array}{c}0.0282 \\
(0.0309)\end{array}$ & $\begin{array}{c}0.0372 \\
(0.0306)\end{array}$ & $\begin{array}{c}0.0351 \\
(0.0305)\end{array}$ \\
\hline Income & $\begin{array}{l}-0.0740 \\
(0.0572)\end{array}$ & $\begin{array}{l}-0.0773 \\
(0.0574)\end{array}$ & $\begin{array}{l}-0.0879 \\
(0.0577)\end{array}$ & $\begin{array}{l}-0.0395 \\
(0.0291)\end{array}$ & $\begin{array}{l}-0.0416 \\
(0.0288)\end{array}$ & $\begin{array}{c}-0.0461 \\
(0.0290)\end{array}$ \\
\hline Urban or rural & $\begin{array}{l}-0.0126 \\
(0.1451)\end{array}$ & $\begin{array}{l}-0.0566 \\
(0.1463)\end{array}$ & $\begin{array}{l}-0.1192 \\
(0.1478)\end{array}$ & $\begin{array}{l}-0.0036 \\
(0.0763)\end{array}$ & $\begin{array}{l}-0.0250 \\
(0.0753)\end{array}$ & $\begin{array}{r}-0.0608 \\
(0.0748)\end{array}$ \\
\hline Region & $\begin{array}{c}-0.5001^{*} \\
(0.0800)\end{array}$ & $\begin{array}{c}-0.5065^{*} \\
(0.0804)\end{array}$ & $\begin{array}{c}-0.5143^{*} \\
(0.0808)\end{array}$ & $\begin{array}{c}-0.2543^{*} \\
(0.0417)\end{array}$ & $\begin{array}{r}-0.2545^{*} \\
(0.0413)\end{array}$ & $\begin{array}{r}-0.2576^{*} \\
(0.0412)\end{array}$ \\
\hline Networks & - & - & $\begin{array}{l}0.3041^{*} \\
(0.0624)\end{array}$ & - & - & $\begin{array}{c}0.1555^{*} \\
(0.0328)\end{array}$ \\
\hline Trust & - & - & $\begin{array}{l}0.1578^{* *} \\
(0.0628)\end{array}$ & - & - & $\begin{array}{c}0.0692^{* *} \\
(0.0330)\end{array}$ \\
\hline Norms & - & - & $\begin{array}{l}0.1495^{* *} \\
(0.0599)\end{array}$ & - & - & $\begin{array}{c}0.0798^{*} \\
(0.0305)\end{array}$ \\
\hline Capital & - & $\begin{array}{l}0.5026^{*} \\
(0.1005)\end{array}$ & - & - & $\begin{array}{l}0.2426^{*} \\
(0.0509)\end{array}$ & - \\
\hline _cons & - & - & - & $\begin{array}{l}2.1500^{*} \\
(0.1899)\end{array}$ & $\begin{array}{l}2.2114^{*} \\
(0.1872)\end{array}$ & $\begin{array}{l}2.2086^{*} \\
(0.1872)\end{array}$ \\
\hline$F / x^{2}$ & 108.64 & 134.19 & 145.62 & 15.32 & 17.46 & 16.38 \\
\hline Prob & 0.0000 & 0.0000 & 0.0000 & 0.0000 & 0.0000 & 0.0000 \\
\hline$R^{2} /$ Pseuxdo $R^{2}$ & 0.0428 & 0.0529 & 0.0574 & 0.0983 & 0.1197 & 0.1314 \\
\hline
\end{tabular}

Note. $^{*}$ and ${ }^{* *}$, respectively, represent the significance levels of $1 \%$ and $5 \%$; data within () is robust standard errors.

only give limited information on significance and symbols, this research further estimates the marginal effect of each variable, in order to directly identify each variable's influence on the citizens' willingness to participate in social governance, as shown in Table 6.

Based on the combination of Tables 5 and 6, the empirical conclusion is drawn as follows:
(1) The influence of social networks on the citizens' willingness to participate in social governance. In general, there is also a significant positive correlation between the social networks and the citizens' willingness to participate in social governance, namely, the more abundant the social networks are, the stronger the willingness of citizen participation in 
TABLe 6: Marginal effect of the ordinal logistic model.

\begin{tabular}{|c|c|c|c|c|c|c|c|c|}
\hline \multirow{2}{*}{ Variables } & \multicolumn{2}{|c|}{ Categorial level $=1$} & \multicolumn{2}{|c|}{ Categorial level $=2$} & \multicolumn{2}{|c|}{ Categorial level $=3$} & \multicolumn{2}{|c|}{ Categorial level $=4$} \\
\hline & Margin & Std. err. & Margin & Std. err. & Margin & Std. err. & Margin & Std. err. \\
\hline Gender & $0.0997^{*}$ & 0.0281 & $0.0050^{* * *}$ & 0.0030 & $-0.0771^{*}$ & 0.0218 & $-0.0276^{*}$ & 0.0080 \\
\hline Age & 0.0162 & 0.0149 & 0.0010 & 0.0010 & -0.0126 & 0.0116 & -0.0045 & 0.0042 \\
\hline Education & $-0.1112^{*}$ & 0.0184 & $-0.0063^{* * *}$ & 0.0033 & $0.0865^{*}$ & 0.0148 & $0.0310^{*}$ & 0.0057 \\
\hline Political status & $-0.0895^{*}$ & 0.0284 & $-0.0080^{* * *}$ & 0.0043 & $0.0702^{*}$ & 0.0227 & $0.0272^{*}$ & 0.0097 \\
\hline Occupation & -0.0115 & 0.0140 & -0.0007 & 0.0009 & 0.0090 & 0.0109 & 0.0032 & 0.0039 \\
\hline Income & 0.0202 & 0.0133 & 0.0012 & 0.0010 & -0.01575 & 0.0104 & -0.0056 & 0.0037 \\
\hline Urban or rural & 0.0277 & 0.0345 & 0.0013 & 0.0014 & -0.0214 & 0.0266 & -0.0075 & 0.0091 \\
\hline Region & $0.1185^{*}$ & 0.0188 & $0.0068^{* *}$ & 0.0035 & $-0.0922^{*}$ & 0.0152 & $-0.0330^{*}$ & 0.0058 \\
\hline Networks & $-0.0701^{*}$ & 0.0143 & $-0.0040^{* * *}$ & 0.0022 & $0.0545^{*}$ & 0.0115 & $0.0195^{*}$ & 0.0043 \\
\hline Trust & $-0.0364^{* *}$ & 0.0145 & -0.0021 & 0.0013 & $0.0283^{* *}$ & 0.0113 & $0.0101^{* *}$ & 0.0041 \\
\hline Norms & $-0.0344^{* *}$ & 0.0138 & -0.0020 & 0.0012 & $0.0268^{* *}$ & 0.0108 & $0.0096^{* *}$ & 0.0039 \\
\hline Capital & $-0.1163^{*}$ & 0.0233 & $-0.0058^{* * *}$ & 0.0034 & $0.0896^{*}$ & 0.01844 & $0.0326^{*}$ & 0.0071 \\
\hline
\end{tabular}

${ }^{*},{ }^{* *}$, and ${ }^{* * *}$, respectively, represent the significance levels of $1 \%, 5 \%$, and $10 \%$.

social governance is. The reasons are as follows: social networks are a kind of intangible resources, the citizens who possess abundant social networks could easily maintain and timely share the information on social governance through social networks; as a result, frequent social interactions may boost the information exchange among the citizens, so as to mitigate the risk of asymmetric information, reduce the cost of participation at a certain degree, and to realize individual development and improvement of life through enriched social networks; thus, the citizens "make a profit by utilizing some sort of resources owned by others" [5], and then the willingness of citizen participation will be promoted. Under such circumstances, the more enriched the social networks are, the more information that the citizens could obtain from social governance and the higher the efficiency will be; in addition, if the social networks could be utilized effectively that the public could benefit from them, then the willingness of the citizen participation in social governance will be stronger.

On all the different categorical levels, the influence of social networks on the citizens' willingness to participate in social governance is relatively significant. On "categorical level = 1" and "categorical level = 2," they are displayed as negative correlations, whereas on "categorical level = 3 " and "categorical level $=4$," they are displayed as positive correlations. To the public of the first three categorical levels $(1,2,3)$, social networks promote the willingness of the citizen participation step-by-step, which further proves that the willingness of citizen participation will be promoted as long as the degree of social networks increases; therefore, the willingness relies on the maturity of the social networks to a relatively great degree. However, on "categorical level $=4$," the influence slightly drops off, which might because of the "interest" factor which is usually valued more than other factors to the interest-driven citizens when making decisions.
(2) The influence of social capital on the citizens' willingness to participate in social governance. In general, there is a significant positive correlation between the social capital and the citizens' willingness to participate in social governance, namely, the more the stock of social capital is, the stronger the willingness of citizen participation in social governance is. It is mostly because, the citizen participation in social governance in China is still in its primary stage, which means the degree of participation is relatively limited; the willingness of citizen participation in social governance will be apparently affected by the cost-benefit factor to a great extent, so the more the stock of social capital is, the less the transaction costs for the citizens to participate in social governance will be, the lower the costs of participation will be, the less the risk of asymmetric information will be, and the greater probability of collective action will be, which will accelerate the process of turning willingness of participation into action; therefore, the willingness of citizen participation in social governance is largely reliable on the stock of social capital.

On different categorical levels, the influence of social capital on the citizens' willingness to participate in social governance shows a tendency of gradually strengthening: on "categorical level $=1$ " and "categorical level $=2$," the influence of social capital on the willingness of citizen participation in social governance is a negative correlation, while on "categorical level $=3$ " and "categorical level $=4$," there is a positive correlation. To the citizens on the first three categorical levels, the influence of social capital on the willingness of participation is gradually increasing, which indicates that, with the increase of the stock of social capital, the willingness of citizen participation in social governance increases. The influence of social trust and social norms on the citizens' willingness is as follows:

(1) The influence of social trust on the citizens' willingness to participate in social governance: 
there is also a significant positive correlation between social trust and the citizens' willingness to participate in social governance, that is, the higher the degree of social trust is, the stronger the willingness of citizen participation is. That is because the pattern of multiple participants has been formed that may lead to collective actions in China, which are greatly reliable on the degree of trust, for "other things being equal, the greater the communication (both direct and indirect) among participants is, the greater their mutual trust and the easier they will find it to cooperate" [42], and social trust could promote the probability of voluntary cooperation among members through mutual influences. In addition, most of the citizen participations in social governance are voluntary, whose effect and quality depend on the mutual cooperation, which cannot be separated from the support of mutual trust [43-45]. On different categorical levels, social trust has different levels of influence on the citizens' willingness to participate in social governance: on "categorical level =2," there is no significant influence of social trust on strong-engaging citizens, with the possible reason that, to strongengaging citizens, the degree of participation are greatly influenced by their original motivations or jobs (tasks); therefore, they are not sensitive to other external factors; on "categorical level $=1$," there is a negative correlation between social trust and the willingness of citizen participation in social governance, whereas on "categorical level = 3" and "categorical level = 4," the correlations turn into positive and the reliable level of the willingness on social trust is relatively high, which further proves that, with the increase of social trust level, the willingness of citizen participation in social governance increases accordingly, especially to the citizens of latter two categorical levels (limited participation), who have more options [46].

(2) The influence of social norms on the citizens' willingness to participate in social governance: in general, there is also a significant positive correlation between the social norms and the willingness of citizen participation in social governance, namely, the higher the degree of social norms is, the stronger the willingness of citizen participation in social governance is. The current phenomenon of disordered participation and symbolic participation are largely because of the absence of social norms in China. For an orderly citizen participation in social governance, on one hand the social norms are the reciprocal norms, with the networks as basis and the trust as the core, which could provide the citizens with benign social norms and orders to engage in, accelerate the citizens to concur with a certain policy decision, and remove the barriers of citizen participation, thereby promote the willingness of citizen participation in social governance; on the other hand, social norms reflect individuals' consent with the referent group on its decision-making behavior, then obeying the norms will earn respect and reputation within the group; otherwise, they would be possible to be excluded and isolated. Consequently, the social norms will constrain the individuals' behavior of participation in social governance and motivate the citizens to obey the public interest instead of certain personal interest; thus, their willingness of participation will be promoted effectively. It indicates that the higher the degree of social norms is, the more powerful the institution and order of citizen participation are, the greater the consent of participating into decision-making is, and the stronger the willingness of participation is.

The influence of social norms on the citizens' willingness to participate in social governance differentiates on different categorical levels: just like the social trust, on "categorical level $=2$," social norms does not impact significantly on the participation willingness of "strong-participation" type, with the possible reason that, to the citizens of this type, their own participation willingness is relatively strong because of their original motivations or jobs (tasks); therefore, they rely less on the maturity of social norms. Likewise, on "categorical level =1," there is a negative correlation between social norms and participation willingness, whereas on "categorical level $=3$ " and "categorical level $=4$," the correlation turns into positive, and the participation willingness relies more on the social norms, which further verifies that, with the increasing social norms, the willingness of citizen participation in social governance enhances accordingly, especially to the citizens of the latter two categorical levels; in addition, the maturity of social norms apparently improves the willingness of citizen participation in social governance.

(3) The influence of demographic characteristics on the citizens' willingness to participate in social governance. In general, there is a significant correlation between the gender, education, political status, region factors, and the citizens' willingness to participate in social governance, while there is no such significant correlation between the age, occupation, income, urban or rural status factors, and the willingness. Specifically, (1) gender factor has significant impact on the willingness of citizen participation in social governance. Compared with the male citizens, the female citizens have weaker willingness and the impact differentiates on different categorical levels, and it may be mainly because of the different gender roles given by the society that the male citizens are more appropriate 
for the management in political and public affairs; therefore, the male citizens have stronger willingness (in China, men and women are endowed with different roles by the society. This is due to the influence of the superiority of men and the inferiority of women in Chinese traditional Confucian culture, that is, men play a dominant role in family and social life, while women are in a subordinate position. Therefore, politics and public affairs are suitable places for typical male characteristics). (2) There is a positive correlation between education and the willingness, and with the increase of the willingness, education has more significant impact on the citizens' willingness to participate in social governance, which indicates that the more educated the citizens are, the stronger their willingness of participating in social governance is. The reason lies in that the more educated citizens will act in a more rational way, their degree of self-identification is higher, their ability of participation is higher, and they have more opportunities to participate in [47]. (3) Political status factor has significant impact on the willingness. Compared to the citizens with nonCPC membership, the citizens with CPC membership have stronger willingness of participation, and the citizens on different categorical levels differentiate on the participation willingness. The main reason may lie in that CPC party members regularly or irregularly attend various kinds of studies or activities, which may dramatically improve the willingness of citizen participation in social governance. (4) Region factor has significant impact on the willingness of citizen participation. Compared to the citizens from the Eastern region, the citizens from Central and Western in China have lower willingness, and the citizens on different categorical levels differentiate on the participation willingness. The main reason lies in that the division of regions were much based on the economic development level, which may be shown as the " $U$ " characteristic among Eastern, Central, and Western regions, and higher level of political participation is always accompanied with higher level of development, and political participation tends to be evaluated higher in a society of greater socioeconomic development. Therefore, the willingness of participation in the relatively developed Eastern region is stronger than that in the less developed Central and Western regions.

\section{Discussion}

Social networks have a significant impact on the citizens' willingness to participate in social governance, as well as the gender, education, political status, and region factors of demographic characteristics, while age, occupation, income, and urban or rural status factors do not. The primary conclusions are as follows. (1) Social networks are invisible resources, the citizens who own abundant social networks are easy to obtain and to share the relevant information of social governance timely through the social networks, while frequent social interaction could boost the width, depth, and efficiency of information exchange among the citizens, to effectively mitigate the risk of asymmetric information and the cost of participation, and to improve the benefit, thereby enhance the willingness of citizen participation. In addition, the strength of the willingness of citizen participation relies on the maturity of social networks greatly. (2) Social capital composed of social networks, social trust, and social norms will also have a significant impact on the citizens' willingness to participate in social governance. The higher stock of social capital means lower transaction costs for the citizens to participate in social governance, lower participation costs, lower risk of asymmetric information, and greater probability of collective actions, which in all will accelerate the process of turning the willingness of citizen participation into action; therefore, to a large extent, the willingness of citizen participation in social governance relies on the stock of social capital, namely, with the increase of the stock of social capital, the willingness of citizen participation in social governance is strengthened. In addition, the other two components of social capital also influence the willingness of citizen participation through social networks. (3) The age, occupation, income, and urban or rural status factors are not significantly correlated with the citizen participation willingness, while gender, education, political status, and region factors are significantly correlated with that, namely, comparatively, the citizens who are male, well educated, CPC members, and from the Eastern region have stronger willingness of participating in social governance.

Compared with the existing literature, more studies focus on political participation or social participation, reflecting the impact on policy agenda and government behavior. China's social governance is a kind of governance oriented by people's livelihood services, with distinct Chinese characteristics. The citizen participation in social governance is different from the traditional political participation and social participation. It is a kind of public participation relying on the community and preferring to the public service supply decision-making, which is also reflecting Chinese wisdom and citizen participation's Chinese characteristics. At the same time, China's social network also has its own characteristics. Therefore, the influence of China's social networks on the citizens' willingness to participate in social governance has a strong sample significance is studied, which may provide useful reference and enlightenment for the citizen participation in other countries all over the world.

Due to the limited energy and ability, the samples selected in this research are limited. There are still some defects and deficiencies in the representativeness and typicality of the samples, which need to be further improved in the future.

\section{Data Availability}

The data used to support the findings of the study are available from the corresponding author upon request. 


\section{Conflicts of Interest}

The authors declare that they have no conflicts of interest.

\section{Acknowledgments}

This study was supported by the National Social Science Fund of China (Grant no. 18CGL033). We also gratefully acknowledge many useful suggestions by Iveta Reinholde.

\section{References}

[1] B. P. Bourdieu, "The forms of capital," in Handbook of Theory and Research for the Sociology of Capital, J. G. Richardson, Ed., pp. 241-258, Greenwood Press, New York, NY, USA, 1986.

[2] M. S. Granovetter, "The strength of weak ties," American Journal of Sociology, vol. 78, no. 6, pp. 1360-1380, 1973.

[3] R. D. Putnam, Bowling Alone: The Collapse and Revival of American Community, Simon \& Schuster, New York, NY, USA, 2000.

[4] I. Ajzen and M. Fishbein, "Scaling and testing multiplicative combinations in the expectancy-value model of attitudes," Journal of Applied Social Psychology, vol. 38, no. 9, pp. 2222-2247, 2008.

[5] A. Portes, "Social capital: its origins and applications in modern sociology," Annual Review of Sociology, vol. 24, no. 1, pp. 1-24, 1998.

[6] M. Li, "Social network and social capital in leadership and management research: a review of causal methods," The Leadership Quarterly, vol. 24, no. 5, pp. 638-665, 2013.

[7] J. Nahapiet and S. Ghoshal, "Social capital, intellectual capital, and the organizational advantage," The Academy of Management Review, vol. 23, no. 2, pp. 242-266, 1998.

[8] J. S. Coleman, "Social capital in the creation of human capital," The American Journal of Sociology, vol. 94, no. suppl, pp. 95-120, 1988.

[9] R. D. Putnam, "What makes democracy work?" National Civic Review, vol. 82, no. 2, pp. 101-107, 1993.

[10] N. Lin, "Building a network theory of social capital," Connections, vol. 22, no. 1, pp. 28-51, 1999.

[11] F. Fukuyama, "Social capital and civil society," in Proceedings of the No. 00/74, IMF Working Papers, International Monetary Fund, Washington, DC USA, March 2000, https:// EconPapers.repec.org/RePEc:imf:imfwpa:00/74.

[12] E. Ostrom, "Collective action and the evolution of social norms," Journal of Economic Perspectives, vol. 14, no. 3, pp. 137-158, 2000.

[13] E. L. Glaeser, D. Laibson, and B. Sacerdote, "An economic approach to social capital," The Economic Journal, vol. 112, no. 483 , pp. $437-458,2003$.

[14] J. M. Roberts and F. Devine, "Some everyday experiences of voluntarism: social capital, pleasure, and the contingency of participation," Social Politics: International Studies in Gender, State \& Society, vol. 11, no. 2, pp. 280-296, 2004.

[15] Q. Fu, Trust, Social Capital, and Organizational Effectiveness, Master's Thesis, Virginia Polytechnic Institute and State University, Blacksburg, Virginia, 2004.

[16] G. A. Brewer, "Building social capital: civic attitudes and behavior of public servants," Journal of Public Administration Research and Theory, vol. 13, no. 1, pp. 5-26, 2003.

[17] M. M. Skoric, D. Ying, and Y. Ng, "Bowling online, not alone: online social capital and political participation in Singapore," Journal of Computer-Mediated Communication, vol. 14, no. 2, pp. 414-433, 2009.
[18] M.-C. Torri, "Community-based enterprises: a promising basis towards an alternative entrepreneurial model for sustainability enhancing livelihoods and promoting socio-economic development in rural India," Journal of Small Business \& Entrepreneurship, vol. 23, no. 2, pp. 237-248, 2010.

[19] K. K. Fung and S. L. Hung, "Strengthening a community of poverty in an affluent society: strategies to build social capital in Tin Shui Wai North in Hong Kong," Community Development Journal, vol. 49, no. 3, pp. 441-457, 2014.

[20] D. Asteria, A. Halimatussadiah, fnm. Budidarmono, D. Utari, and R. Dwi Handayani, "Relation of social capital to women's proactive participation in the community for sustainability of river in urban areas," E3s Web of Conferences, vol. 73, Article ID 03003, 2018.

[21] H. Suh and R. S. Heidi, "A contingent effect of trust? Interpersonal trust and social movement participation in political context," Social Science Quarterly, vol. 99, no. 4, pp. 1484-1495, 2018.

[22] H. Zúñiga, N. Jung, and S. Valenzuela, "Social media use for news and individuals' social capital, civic engagement and political participation," Journal of Computer-Mediated Communication, vol. 17, no. 3, pp. 319-336, 2012.

[23] Y. Hu, F. Xiong, S. Pan, X. Xiong, L. Wang, and H. Chen, "Bayesian personalized ranking based on multiple-layer neighborhoods," Information Sciences, vol. 542, pp. 156-176, 2021.

[24] F. Xiong, W. Shen, H. Chen, S. Pan, X. Wang, and Z. Yan, "Exploiting implicit influence from information propagation for social recommendation," IEEE Transactions on Cybernetics, vol. 50, 2019.

[25] Z. Li, F. Xiong, X. Wang, H. Chen, and X. Xiong, "Topological influence-aware recommendation on social networks," Complexity, vol. 2019, Article ID 6325654, 12 pages, 2019.

[26] P. S. Adler and S.-W. Kwon, "Social capital: prospects for a new concept," Academy of Management Review, vol. 27, no. 1, pp. 17-40, 2002.

[27] C. Boix and D. N. Posner, "Social capital: explaining its origins and effects on government performance," British Journal of Political Science, vol. 28, no. 4, pp. 686-693, 1998.

[28] D. Gambetta, Trust: Making and Breaking Cooperative Relations, Vol. 217, Basil Blackwell, New York, NY, USA, 1988.

[29] S. E. S. Crawford and E. Ostrom, "A grammar of institutions," American Political Science Review, vol. 89, no. 3, pp. 582-600, 1995.

[30] M. S. Granovetter, "Economic action and social structure: the problem of embeddedness," The American Journal of Sociology, vol. 91, no. 3, pp. 482-510, 1985.

[31] K. L. Schlozman, N. Burns, and S. Verba, "Gender and the pathways to participation: the role of resources," The Journal of Politics, vol. 56, no. 4, pp. 963-990, 1994.

[32] N. Roberts, "Public deliberation in an age of direct citizen participation," The American Review of Public Administration, vol. 34, no. 4, pp. 315-353, 2004.

[33] J. Kim, "The Impacts of social capital on civic participative institution's effectiveness," Korean Public Administration Quarterly, vol. 23, no. 9, pp. 1007-1031, 2011.

[34] P. Paxton, "Social capital and democracy: an interdependent relationship," American Sociological Review, vol. 67, no. 2, pp. 254-277, 2002.

[35] R. D. Putnam, "The prosperous community: social capital and public life," The American Prospect, vol. 13, no. 4, pp. 35-42, 1993.

[36] C. Grootaert and T. van Bastlaer, Understand and Measuring Social Capital, World Bank, Washington, DC, USA, 2002. 
[37] T. Harpham, "The measurement of community socialcapital through surveys," in Social Capital and Health, I. Kawachi, S. Subramanian, and D. Kim, Eds., Springer, New York, NY, USA, 2007.

[38] F. Sabatini, "Social capital as social networks: a new framework for measurement and an empirical analysis of its determinants and consequences," The Journal of SocioEconomics, vol. 38, no. 3, pp. 429-442, 2009.

[39] C. F. Baum, An Introduction to Modern Econometrics Using Stata, Stata Press books, College Station, TX, USA, 2006.

[40] S. R. Arnstein, "A ladder of citizen participation," Journal of the American Institute of Planners, vol. 35, no. 4, pp. 216-224, 1969.

[41] A. Ferrer-i-Carbonell and P. Frijters, "How important is methodology for the estimates of the determinants of happiness?" The Economic Journal, vol. 114, no. 497, pp. 641-659, 2004.

[42] R. D. Putnam, Making Democracy Work: Civic Tradition In Modern Italy, Vol. 173, Princeton University Press, Princeton, NY, USA, 1993.

[43] C. D. De and T. R. Tyler, "The effects of trust in authority and procedural fairness on cooperation," Journal of Applied Psychology, vol. 92, no. 3, pp. 639-649, 2007.

[44] M. J. Hetherington, Why Trust Matters: Declining Political Trust and the Demise of American Liberalism, Princeton University Press, Princeton, NY, USA, 2005.

[45] J. Delhey and K. Newton, "Who trusts? The origins of social trust in seven societies," European Societies, vol. 5, no. 2, pp. 93-137, 2003.

[46] L. Guiso, P. Sapienza, and L. Zingales, "The role of social capital in financial development," American Economic Review, vol. 94, no. 3, pp. 526-556, 2004.

[47] M. M. Conway, "Political participation in the United States," Political Psychology, vol. 7, no. 4, p. 807, 1991. 